\title{
A reusable, custom-made warming blanket prevents core hypothermia during major neonatal surgery
}

\author{
[Une couverture chauffante réutilisable, faite sur mesure, prévient l'hypothermie \\ centrale pendant une intervention chirurgicale néonatale importante]
}

Suneerat Kongsayreepong MD, ${ }^{*}$ Panidaporn Gunnaleka RN BSC, $†$ Suwannee Suraseranivongse MD MSC, * Sangsom Pirayavaraporn MD, ${ }^{*}$ Sumitra Chowvanayotin MD, ${ }^{*}$ Thunyanit Montapaneewat RN BSC, ${ }^{*}$ Chitprapa Manon RN BSC*

Purpose: To introduce a reusable model of neonatal forced air warming blanket for intraoperative use during major noncardiac neonatal surgery and to determine clinical efficacy of this reusable blanket compared with the commonly used disposable blankets.

Methods: Delivered air temperature and calorie uptake of standard thermal bodies within the reusable blankets, Bair Hugger ${ }^{\circledR}$ blanket model 530 and model 555 were studied. Also, an efficacy study was conducted in 90 neonatal patients scheduled for major noncardiac surgery comparing the reusable blanket, the Bair Hugger ${ }^{\circledR}$ blanket model 530 and passive heat conservation as a control. The covered reusable blanket was used as a rescue procedure if the core temperature was $<35.5^{\circ} \mathrm{C}$.

Results: Delivered air temperature and heat transfer from the covered reusable blanket did not differ significantly from those of the Bair Hugger ${ }^{\circledR}$ blanket model 530 and model 555 (despite $0.75^{\circ} \mathrm{C}-1.2^{\circ} \mathrm{C}$ of heat trapped under the sheet and $1.3 \mathrm{Kcal}$ less energy transfer). Temperatures measured underneath patients (correlated to poorly perfused areas) were highest using the Bair Hugger $\AA$ blanket model 555 . The reusable blanket was efficacious in preventing intraoperative core hypothermia and not different from the Bair Hugger $\AA$ blanket model 530. About I/3 of the patients in the control group had presented a core temperature < $35.5^{\circ} \mathrm{C}$ but were successfully rescued using the reusable blanket. No adverse events were associated with any of these warming methods.

Conclusion: This study shows the clinical efficacy of our reusable blanket for the prevention of core hypothermia during major neonatal surgery, which is not different from commonly used disposable blankets.
Objectif : Présenter un modèle réutilisable de couverture chauffante à air forcé employée pendant une opération néonatale non cardiaque et déterminer l'efficacité clinique de cette couverture comparée aux couvertures jetables généralement utilisées.

Méthode : Nous avons étudié la température de l'air fourni et l'échange calorique à des corps thermiques normaux à l'intérieur des modèles 530 et 555 de couvertures réutilisables Bair Hugger ${ }^{\circledR}$. De plus, une étude d'efficacité a été réalisée auprès de 90 nouveau-nés devant subir une opération non cardiaque importante en comparant la couverture réutilisable, le modèle 530 Bair Hugger $\AA$ et un mode de conservation de chaleur passif comme témoin. La couverture réutilisable étudiée a été utilisée comme mesure de secours lorsque la température centrale était $<35,5^{\circ} \mathrm{C}$.

Résultats : La température de l'air fourni et le transfert de chaleur par la couverture réutilisable étaient comparables à ceux des modèles 530 et 555 de Bair Hugger ${ }^{\circledR}$ (malgré $0,75^{\circ} \mathrm{C}-1,2^{\circ} \mathrm{C}$ de chaleur retenue sous la couverture et $1,3 \mathrm{Kcal}$ de transfert d'énergie en moins). Les températures mesurées sous les patients (correspondaient aux zones mal perfusées) ont été plus élevées avec le modèle 555 de Bair Hugger ${ }^{\circledR}$. La couverture réutilisable a été efficace pour prévenir I'hypothermie centrale peropératoire et comparable au modèle 530 de Bair Hugger $\AA$. Environ 1/3 des patients du groupe témoin ont présenté une température centrale $<35,5^{\circ} \mathrm{C}$, mais ont été réchauffés avec succès grâce à la couverture réutilisable. Aucun effet indésirable n'a été associé à quelque méthode que ce soit.

Conclusion: L'étude montre l'efficacité clinique de notre couverture réutilisable, comparable à celle des couvertures jetables courantes, pour prévenir l'hypothermie centrale pendant une intervention chirurgicale néonatale importante.

From the Department of Anesthesiology, ${ }^{*}$ and the Department of Surgical Nursing, $†$ Siriraj Hospital, Faculty of Medicine, Mahidol University, Bangkok, Thailand.

Address correspondence to: Dr. Suneerat Kongsayreepong, Department of Anesthesiology, Siriraj Hospital, Faculty of Medicine, Mahidol

University, Bangkok-10700, Thailand, Phone: 02-222-1602; Fax: 02-222-3657; E-mail: sisko@mahidol.ac.th

Accepted for publication January 22, 2002.

Revision accepted March 13, 2002. 
$\mathrm{P}$ REVENTION of core hypothermia during major neonatal surgery is one of the important objectives of neonatal anesthesia. Retrospective reports of forced air warming systems have shown this to be the best way to prevent core hypothermia during neonatal surgery. ${ }^{1,2}$ However, complications can occur, such as skin burns arising from blowing hot air directly onto the skin, especially of poorly perfused areas, ${ }^{3,4}$ a potentially increased risk of infection from a reused blanket which was designed for single use ${ }^{5}$ or from direct blow of hot air from the hose to the patient. ${ }^{6}$ There is also a cost implication of using a disposable blanket. ${ }^{7}$ Also, as more emergency surgery is performed under an overhead radiant heating unit in the neonatal intensive care unit, ${ }^{8}$ effects of using a forced air warming system in addition to the radiant heating unit remain unclear. In order to preserve the benefits of a forced air warming system and to minimize any associated complications and costs, a reusable neonatal forced air warming blanket was designed and introduced for intraoperative use during major noncardiac neonatal surgery at our centre. Delivered air temperature and heat transfer, including the clinical efficacy of this reusable blanket in the prevention of intraoperative core hypothermia was compared with the commonly used disposable neonatal forced air warming blankets under an overhead radiant heating unit.

\section{Materials and methods}

Heated forced air from a Gaymar (Warm Touch ${ }^{\circledR}$, TC3003, Orchard Park, NY, USA) warming unit at $32^{\circ} \mathrm{C}, 38^{\circ} \mathrm{C}, 43^{\circ} \mathrm{C}$ and $46^{\circ} \mathrm{C}$ was delivered through a reusable forced air warming blanket and disposable blankets (Bair Hugger ${ }^{\circledR}$ blanket model 530 and model 555, Eden Prairie, MN, USA) under standard, simulated operating room conditions $\left(24 \pm 1^{\circ} \mathrm{C}\right)$, using a manikin ( $3 \mathrm{~kg}, 60 \mathrm{~cm}$ long) to represent a neonate. Delivered air temperatures (from three locations: cranium, feet and underneath the patient) and calorie uptake of standard thermal bodies containing $1000 \mathrm{~mL}$ Ringers Lactate solution lying within the reusable blanket were compared with those obtained with the disposable blankets.

The reusable blanket (Figure 1) was made of a light to medium weight, water resistant canvas, sewn like a cushion, leaving the cranial end open in order to attach a hose and was designed to be placed underneath the patient. Small holes $\left(1 \mathrm{~mm}^{2}\right), 1 \mathrm{~cm}$ apart were punched on the upper surface of this blanket except for the area underneath the patient that was sewn into tube shapes. This will prevent direct blowing of warm air onto the underside of the patient and

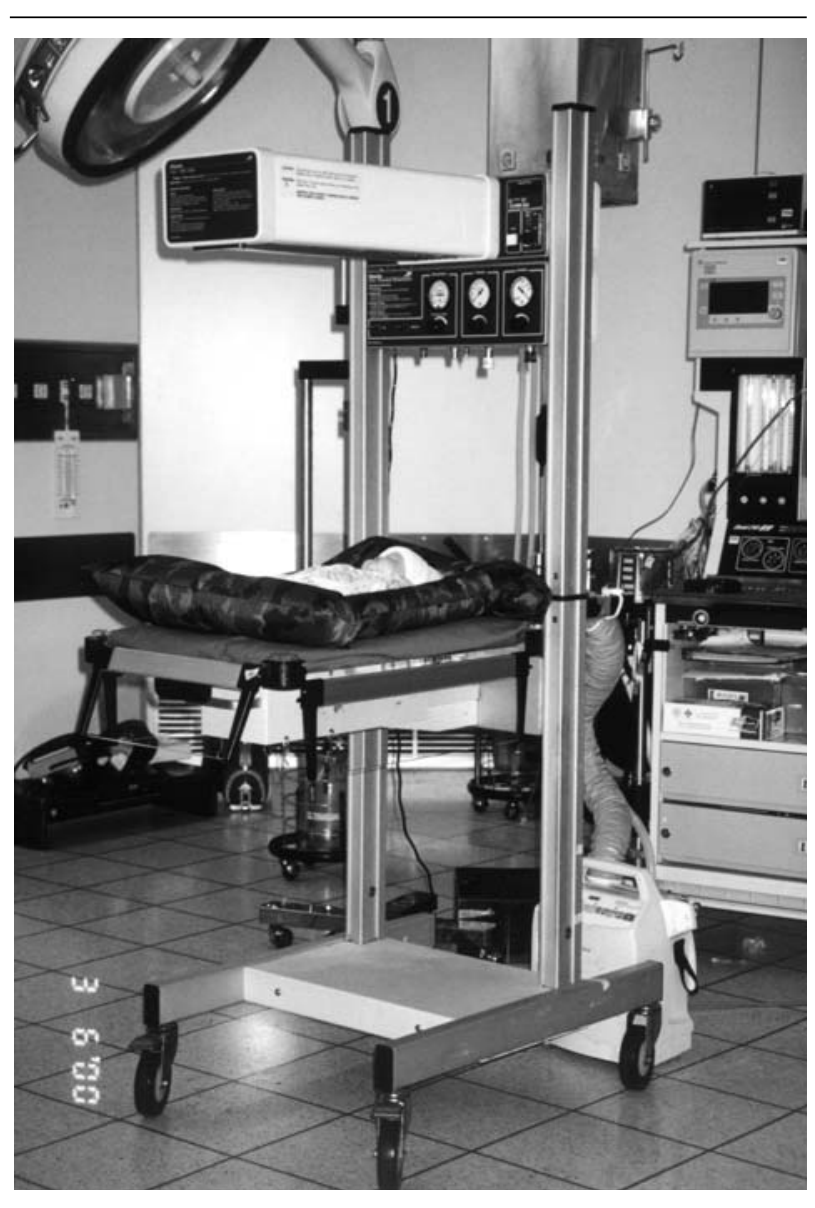

FIGURE 1 Reusable blanket placed underneath a manikin on the modified operating table Neonatal resuscitator (NRT 2000 Omeda Ohio ${ }^{\circledR}$ ) with the warm air delivery hose attached to the cranial end.

the modified canvas tubings provide a warm, even contact surface with a reduced risk of pressure burns. A surgical sheet is placed on top of the blanket with the edges tucked underneath to prevent air leak. Thus, all the warm air circulating under the sheet will be forced upwards through the minute holes of the surgical sheet and will closely surround the patient. ${ }^{9}$ This should minimize burns by preventing hot air from blowing directly onto the delicate skin of the baby and avoiding direct contact of the patient with the blanket. ${ }^{10}$ The blanket is $100 \mathrm{~cm} \times 70 \mathrm{~cm}$ (unfloated) and $50 \mathrm{~cm} \times 80 \mathrm{~cm}$ (floated) fitting a baby while leaving a surrounding area of $15 \mathrm{~cm}$. It can be enlarged to fit an infant up to two years old. In order to reuse it, the blanket can be washed, dried and sterilized by gas or autoclaved for more than 50 times. A sterile sheet will enhance the sterile environment of the operating field. 


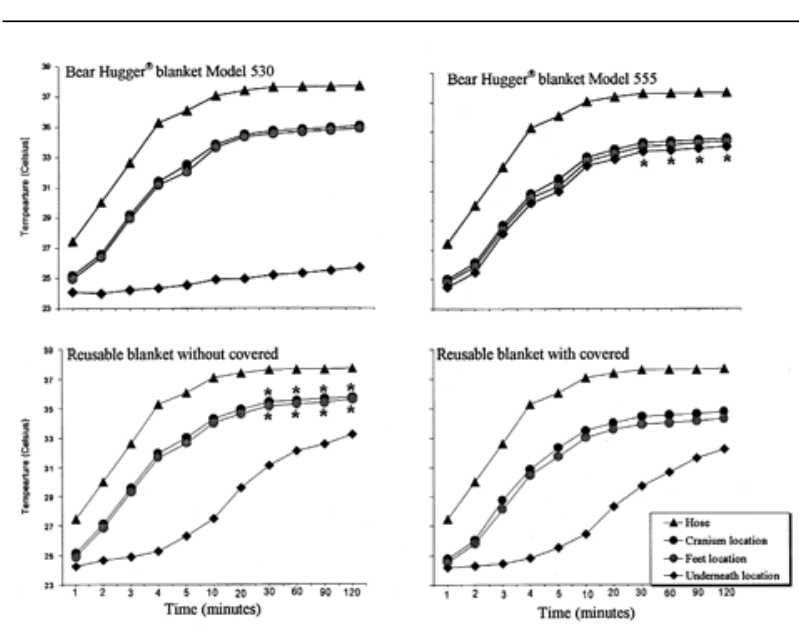

FIGURE 2 Air temperatures with the Bair Hugger ${ }^{\circledR}$ blanket model 530, Bair Hugger ${ }^{\circledR}$ blanket model 555, reusable blanket and reusable blanket covered with a surgical sheet. Temperatures were measured at the cranium $\left(\mathrm{T}_{\text {cranium }}\right)$, feet $\left(\mathrm{T}_{\text {feet }}\right)$, and underneath the patient $\left(\mathrm{T}_{\text {underneath }}\right)$ using the $38^{\circ} \mathrm{C}$ temperature setting on the warming unit.

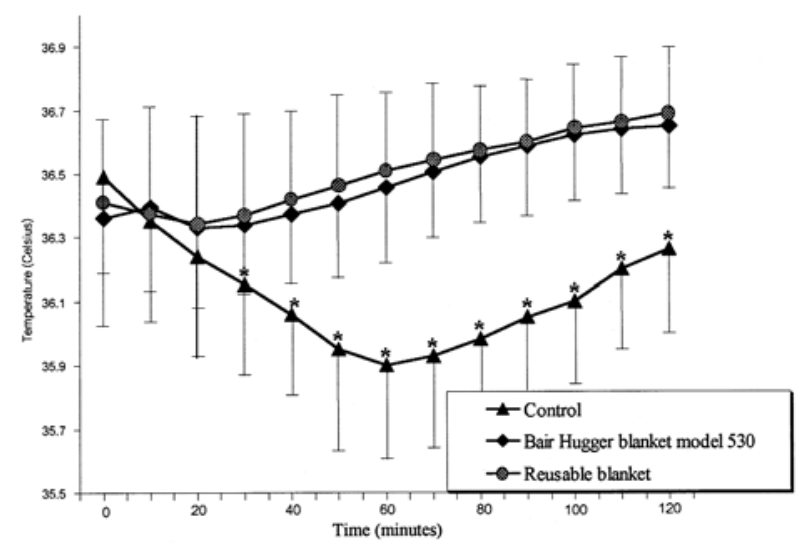

FIGURE 3 Core temperature (mean \pm SD) of the control group $(n=30)$, Bair Hugger blanket model 530 group $(n=30)$ and reusable blanket covered with a surgical sheet $(n=30),{ }^{*} P<$ 0.001 vs the Bair Hugger ${ }^{\circledR}$ blanket model 530 group and the reusable blanket with surgical sheet covering.

The cost of this blanket (materials and labour) was $\$ 4$ US plus \$2 US per sterilization in our department.

The Bair Hugger ${ }^{\circledR}$ blanket model 530 is a disposable blanket which is placed around the patient and, when combined with a heating unit, provides warm air coming sidewards, surrounding the patient.
The Bair Hugger® blanket model 555 is a disposable blanket which is placed underneath the patient and provides warm air coming upwards and surrounding the patient.

After obtaining approval from the Ethical Committee of Human Rights, Faculty of Medicine, Siriraj Hospital and informed consent, 90 neonates scheduled for major noncardiac surgery were randomly allocated by blocked randomization to one of three groups according to the warming method used: 1) reusable forced air warming blanket; 2) Bair Hugger ${ }^{\circledR}$ blanket model 530; and 3 ) a control group (passive heat conservation method). An overhead radiant heating unit (modified Ohmeda Ohio ${ }^{\circledR}$ Neonatal Resuscitator [NRU] 2000, Milan, Italy) was used in all cases while room temperature was maintained at $24 \pm 1^{\circ} \mathrm{C}$. Core (distal esophagus or rectal) and skin temperatures (calf and big toe) were monitored throughout the study period and immediately afterwards in the recovery room. The covered reusable blanket was used as a rescue procedure if the core temperature was $<35.5^{\circ} \mathrm{C}$.

Data were analyzed using the SPSS 10.0 program. A repeat-measure ANOVA with Scheffe study and Chi square tests were performed to compare the groups studied. Statistical significance was defined as $P<0.05$.

\section{Results}

Delivered air temperatures within the blankets (Figure 2 ) at the cranium and feet increased rapidly, reaching a plateau at $25-30 \mathrm{~min}$. When the reusable blanket was covered with a surgical drape, temperatures of $0.75^{\circ} \mathrm{C}$ and $1.2^{\circ} \mathrm{C}$ lower than that delivered by the warming unit were recorded at the cranium and feet. These were not different from those obtained with the disposable blankets. Temperatures underneath the manikin were significantly higher using the Bair Hugger ${ }^{\circledR}$ blanket model 555. The lowest were found with the Bair Hugger ${ }^{\circledR}$ blanket model 530 while those resulting from the reusable blanket increased slowly with a temperature of $10^{\circ} \mathrm{C}$ less than delivered temperature at 120 min and another $1^{\circ} \mathrm{C}$ less when the reusable blanket was covered with a surgical sheet. The calorie uptake of the standard thermal bodies was highest with the reusable blanket $\left(9.70 \pm 0.14 \mathrm{Kcal} ; P=0.012\right.$ at $38^{\circ} \mathrm{C}$ and $13.75 \pm 0.07 \mathrm{Kcal} ; P=0.018$ at $43^{\circ} \mathrm{C}$ ) and was reduced by $1.3 \mathrm{Kcal}$ when the blanket was covered $p s$ Bair Hugger ${ }^{\circledR}$ blanket model 555, Bair Hugger ${ }^{\circledR}$ blanket model 530 and the reusable blanket with a surgical sheet covered. This was not different from heat exchange using the disposable blankets.

There were no statistically significant differences in the baseline characteristics between groups of neonates (Table). The covered reusable forced air warming blan- 
TABLE Baseline characteristics of the studied patients (mean \pm SD)

\begin{tabular}{|c|c|c|c|c|}
\hline Parameter & Control & Bair Hugger ${ }^{\circledR}$ blanket model 530 & Reusable blanket & Pvalue \\
\hline Age (day) & $\begin{array}{l}6.53 \pm 6.90 \\
(\text { range, } 1-29)\end{array}$ & $\begin{array}{l}5.66 \pm 5.97 \\
(\text { range, } 1-24)\end{array}$ & $\begin{array}{l}5.20 \pm 4.59 \\
(\text { range, } 1-15)\end{array}$ & 1.000 \\
\hline Sex (male:female) & $\begin{array}{l}18: 12 \\
(60.0 \%: 40.0 \%)\end{array}$ & $\begin{array}{l}19: 11 \\
(63.3 \%: 36.7 \%)\end{array}$ & $\begin{array}{l}17: 13 \\
(56.7 \%: 43.3 \%)\end{array}$ & 0.870 \\
\hline Weight (g) & $2901.83 \pm 376.85$ & $2946.50 \pm 489.09$ & $2834.33 \pm 276.22$ & 0.541 \\
\hline $\begin{array}{l}\text { Control body } \\
\text { temperature }\end{array}$ & $36.54 \pm 0.22$ & $36.49 \pm 0.10$ & $36.48 \pm 0.11$ & 0.330 \\
\hline Anesthetic time (min) & $116.33 \pm 8.50$ & $115.83 \pm 8.91$ & $112.33 \pm 8.17$ & 0.199 \\
\hline Surgical time $(\min )$ & $105.00 \pm 9.38$ & $104.83 \pm 8.7$ & $99.17 \pm 20.43$ & 0.274 \\
\hline Total amount of fluid & $105.00 \pm 20.43$ & $101.10 \pm 10.86$ & $99.67 \pm 11.21$ & 0.492 \\
\hline Diagnosis & & & & 0.933 \\
\hline Gastroschisis & $6(20.0 \%)$ & $5(16.7 \%)$ & $7(23.3 \%)$ & \\
\hline $\begin{array}{l}\text { Tracheo-esophageal } \\
\text { fistula }\end{array}$ & $2(6.7 \%)$ & $2(6.7 \%)$ & $3(10.0 \%)$ & \\
\hline Duodenal atresia & $2(6.7 \%)$ & $3(10.0 \%)$ & $2(6.7 \%)$ & \\
\hline Gut obstruction & $8(26.7 \%)$ & $10(33.3 \%)$ & $6(20.0 \%)$ & \\
\hline Pyloric stenosis & - & $1(3.3 \%)$ & - & \\
\hline Anorectal malformation & $8(26.7 \%)$ & $7(23.3 \%)$ & $8(26.7 \%)$ & \\
\hline Diaphragmatic hernia & $1(3.3 \%)$ & -- & $2(6.7 \%)$ & \\
\hline Biliary atresia & $2(6.7 \%)$ & $1(3.3 \%)$ & - & \\
\hline Others & $1(3.3 \%)$ & $1(3.3 \%)$ & $2(6.7 \%)$ & \\
\hline Operation & & & & 0.726 \\
\hline Exploratory laparotomy & $21(70.0 \%)$ & $21(70.0 \%)$ & $23(76.7 \%)$ & \\
\hline Exploratory thoracotomy & $3(10.0 \%)$ & $2(6.7 \%)$ & $4(13.3 \%)$ & \\
\hline Pylorotomy & - & $1(3.3 \%)$ & - & \\
\hline Colostomy & $4(13.3 \%)$ & $5(16.7 \%)$ & $3(10.0 \%)$ & \\
\hline Kasai’s operation & $2(6.7 \%)$ & $1(3.3 \%)$ & - & \\
\hline
\end{tabular}

ket was efficacious in preventing intraoperative core hypothermia and was not different from the Bair Hugger ${ }^{\circledR}$ blanket model 530 (Figure 3). The radiant heater could be turned off in 19 patients using the reusable blanket compared with 14 patients using the Bair Hugger ${ }^{\circledR}$ blanket $(P=0.259)$. One third of the patients in the control group exhibited a core temperature $<35.5^{\circ} \mathrm{C}$ (six neonates at $60 \mathrm{~min}$ and seven neonates at $70 \mathrm{~min}$ ). They were successfully rescued using the covered reusable blanket but final temperatures were less than those of the two blanket groups. No adverse events were associated with any warming method used.

\section{Discussion}

Despite heat being trapped under the surgical sheet (1.3 Kcal less energy transferred), the covered reusable blanket used in conjunction with a radiant warmer provided adequate heat transfer and prevented intraoperative hypothermia during major noncardiac neonatal surgery. These results were similar to those obtained with the Bair Hugger ${ }^{\circledR}$ blanket model 530. It also provides evidence that covering the reusable blanket with a surgical sheet maintains adequate heat transfer and prevents core hypothermia. Use of a passive heat conservation method in association with anterior surface warming by a radiant heater did not prevent core hypothermia during major neonatal surgery. However, core hypothermia and thermoregulatory vasoconstriction did not impede successful rewarming using our reusable blanket.

In summary, the reusable blanket designed and introduced at our centre exhibits warming characteristics similar to those of commonly available disposable devices. Our experience in 90 neonates suggests that the reusable blanket effectively prevents core hypothermia, may succeed in rewarming hypothermic neonates and is not associated with an increased incidence of adverse events.

\section{Acknowledgements}

The authors wish to thank Prof. Thara Tri-takarn who has helped support our knowledge and input in this study and our kind pediatric surgeons who provided many constructive comments and allowed us to do this study.

\section{References}

1 Komatsu H, Chujo K, Ogli K. Forced-air warming system for perioperative use in neonates (Letter). Paediatr Anaesth 1996; 6: 427-8. 
2 Schlünzen L, Vestergaard AL, Møller-Nielsen I, Pedersen $J$, Hjortholm K, Sloth E. Convective warming blankets improve peroperative heat preservation in congenital heart surgery. Paediatr Anaesth 1998; 8: 397-401.

3 Azzam FJ, Krock JL. Thermal burns in two infants associated with a forced air warming system (Letter). Anesth Analg 1995; 81: 661.

4 Truell KD, Bakerman PR, Teodori MF, Maze A. Thirddegree burns due to intraoperative use of a Bair Hugger warming device. Ann Thorac Surg 2000; 69: 1933-4.

5 Sigg DC, Houlton AJ, Iaizzo PA. The potential for increased risk of infection due to the reuse of convective air-warming/cooling coverlets. Acta Anaesthesiol Scand 1999; 43: 173-6.

6 Avidan MS, Jones N, Ing R, Khoosal M, Lundgren C, Morrell DF. Convection warmers-not just hot air. Anaesthesia 1997; 52: 1073-6.

7 Fleisher LA, Metzger SE, Lam J, Harris A. Perioperative cost-finding analysis of the routine use of intraoperative forced-air warming during general anesthesia. Anesthesiology 1998; 88: 1357-64.

8 Anveden-Hertzberg L, Gauderer MWL. Surgery is safe in very low birthweight infants with necrotizing enterocolitis. Acta Paediatr 2000; 89: 242-5.

9 Kempen PM. Full body forced air warming: commercial blanket vs air delivery beneath bed sheets. Can J Anaesth 1996; 43: 1168-74.

10 Karayan J, Thomas D, Lacoste L, Dhoste K, Ricco JB, Fusciardi J. Delayed forced air warming prevents hypothermia during abdominal aortic surgery. $\mathrm{Br} \mathrm{J}$ Anaesth 1996; 76: 459-60. 